\title{
Detecting the optimal condition of Zeolite utilization in industrial wastewater treatment by using the fuzzy simulation model
}

Behrouz Abolpour ( $\nabla$ abolpour@gmail.com )

Northwest Institute of Eco-Environment and Resources

Sahar Sheibani

University of Zabol

Amir Eskandari

Islamic Azad University Shiraz

\section{Research}

Keywords: Zeolite, industrial wastewater, fuzzy simulation, optimization

Posted Date: July 9th, 2020

DOI: https://doi.org/10.21203/rs.3.rs-33759/v1

License: (c) (i) This work is licensed under a Creative Commons Attribution 4.0 International License.

Read Full License 
12 Abstract

\title{
Detecting the optimal condition of Zeolite utilization in industrial wastewater
}

\section{treatment by using the fuzzy simulation model}

\author{
Behrouz Abolpour ${ }^{\mathrm{a}}$, Sahar Sheibani ${ }^{\mathrm{b}}$ and Amir Eskandari ${ }^{\mathrm{c}}$
}

Agricultural Engineering Research Department, Fars Agricultural and Natural Resources Research, Agricultural

Research, Education and Extension Organization (AREEO), Shiraz, Iran. Visiting Scientist of Northwest Institute of Eco-Environment and Resources (NIEER), CAS, Lanzhou, China.

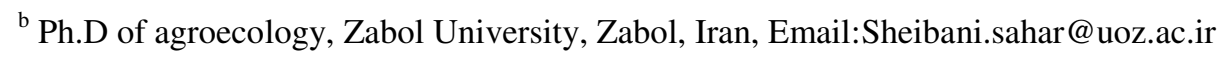

${ }^{c}$ M.S. of geology economic, Azad University, Shiraz, Iran, Email:Amireskandari61@gmail.com.

Corresponding author at: Visiting Scientist of Northwest Institute of Eco-Environment and Resources (NIEER), CAS, Lanzhou, China. Phone: +989177377067. abolpour@gmail.com.

To define optimal condition of Zeolite utilization was used the maximum industrial pollution load from the industrial wastewater discharged to treatment plant lied on the industrial town of Shiraz, Fars, Iran. In this study, chemical oxygen demand (COD) load and electrical conductivity (EC) load from this wastewater treatment plant (WWTP) along with the parameters of received industrial effluents, e.g., temperature, total suspended solid (TSS), total dissolved solid (TDS) and PH were monitored. Using the several mathematical models that defined on their relationships was resulted the correlation coefficients of $83 \%$ and $90 \%$ for COD with TDS, and COD with TSS, respectively, thus the best regression coefficient was 0.5 under linear and nonlinear forms. Autoregressive integrated moving average model (ARIMA) was also used for obtaining the better results, such that the exceeded values of TSS and TDS at before day were 
23 defined as input variables. In this log-time of bioreactor process, curve fitting approach and 24 clustering analysis with and without normalized data had not improved the regression coefficient 25 of linear and nonlinear functions. The simulation model based on fuzzy inference system (FIS) 26 has been good corresponding with the distribution of estimated and observed data of COD, so

27 that comparing such distribution of COD with line of 1:1 resulting the regression coefficient is 28 0.764. This study indicated that fixed value of the soluble solids concentration on industrial 29 wastewater discharged into treatment plant has the important role in effectiveness of Zeolite 30 filtration, i.e., it's threshold is occurred in $1746 \mathrm{ppm}$ in this case study.

31 Key words: Zeolite, industrial wastewater, fuzzy simulation, optimization

\section{Highlight}

- In this paper was presented an approach for defining the optimum condition of Zeolite utilization in WWTP on uncertainty conditions.

- This optimum condition was developed by FIS such that the water quality released from WWTP is enough good to be supplied water requirement of the greenspace.

- It was found that the entered soluble solids concentration into WWTP has important role in the released water quality and the effectiveness of Zeolite filtration. 


\section{Introduction}

The water shortage is a growing problem in the world due to the freshwater resources

47 have been becoming not enough to satisfy the demand. Although the freshwater shortage seems that the most cases of a climate-bound regional problems, it has reported in whole the world, e.g.

49 , North Africa, the Middle East, southern Europe, Australia, and the southern states of the USA.

50 Therefore, during the past few decades, there has been a growing interest in water alternative

51 sources development such as the used urban water and desalinized brackish water and seawater

52 [3]. According to UNESCO-WWAP [33] more than $70 \%$ of the water that is discharge all over

53 the world used for the agricultural irrigation, however there is a big potential for the application

54 of treated wastewater in irrigation [19]. The most important concerns in the agricultural use of 55 treated urban waters [8] are related to the human and environmental health aspects, in other 56 words, the quality and safety of the produced food [23] and the health concerns of agricultural 57 workers. Other concerns include the salinity and water infiltration rate in the soil [36], as well as 58 heavy metal accumulation and pollution caused by nutrient leaching [10]. Nevertheless, the use 59 of treated wastewater is a global phenomenon in a variety of applications in more than fifty countries throughout the world as reported by $[26,12]$.

The key for safe irrigation is the water quality. Many standards have been to set by different institutions to control the quality of the irrigated water. The concentration and composition of the dissolved constituents in water combined with the amount of water used 64 determines its quality for irrigation. Soils also vary in their capacity to resist adverse changes due 65 to the components of the water. A comprehensive water analysis will indicate its suitability for 66 irrigation use [1]. In the literature, oxygen required for the degradation of the organic matter 67 biologically (BOD), the amount of oxygen needed to consume the organic and inorganic 
71

72

73

74

75

76

77

78

79

80

81

82

83

84

\section{2. Material and Methods}

86

87

88

89

materials, chemical oxygen demand (COD), potential of hydrogen $(\mathrm{pH})$, and total suspended solids (TSS) are widely used indicators of wastewater quality [11,38]. Zeolites are safe and naturally occurring crystalline aluminosilicates have a threedimensional structure, which comprise assemblies of $\mathrm{SiO}_{4}$ and $\mathrm{AlO}_{4}$ tetrahedral joined in different regular arrangements through the sharing of oxygen atoms and form a honeycomb structure containing pores $[31,15,14]$. Natural zeolite is a promising adsorbent media has a potential application as a metal ion adsorbent, and has particularly gained interest among researchers, due to its ion exchange, molecular sieve properties and also its relatively high surface area $[21,2]$. The limited studies have been to carry out on the relationship between loaded and exceed parameters of the industrial wastewater treatment by natural zeolite. In this study, the exceeded values of chemical oxygen demand (COD) and electrical conductivity (EC) from the industrial wastewater treatment plant was estimated based on other loaded factors such as PH, temperature, total suspended solid (TSS), total dissolved solid (TDS). These measured values are the given data, but the EC and the COD have considered as unknown variables. The mathematical model of this relationship between these parameters defined.

\subsection{Wastewater station and monitoring}

Water Reclamation Plant (WRP) is located in Shiraz industrial town, Fars, Iran (Fig.1). The pollution points are approximately 1100 units of medium and small factories that released their wastewaters to this plant network with the capacity of $2500 \mathrm{~m} 3$ per day, but the wastewater 


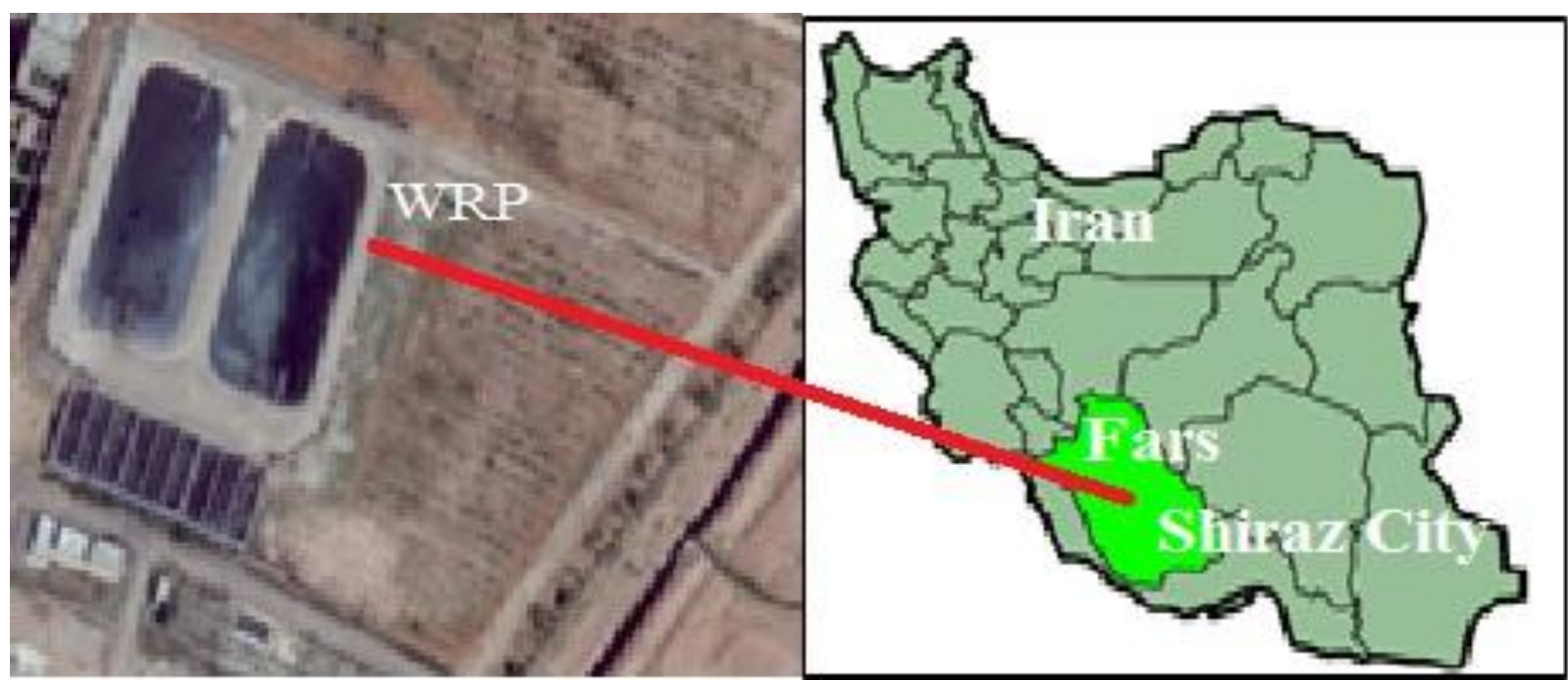

92
Table 1

The characteristics summary of monitored data

\begin{tabular}{cccc}
\hline NO & Parameter & $\begin{array}{c}\text { Analysis } \\
\text { type }\end{array}$ & $\begin{array}{c}\text { Measurement } \\
\text { standard }\end{array}$ \\
\hline 1 & COD & Spectrophotometer & APHA \\
2 & PH & PH meter & APHA \\
3 & EC & EC meter & APHA \\
4 & TSS & Gravimetric & APHA
\end{tabular}


104

105

106

107

108

109

110

111

112

113 114 meaningful conclusions [35, 24, 27, 28].

115

116

117

118

119

120

121

122

123

124

125

\subsection{Modeling the wastewater parameters}

The environmental data characterized by high variations because of a variety of natural and anthropogenic influences. The popular approach to avoid the misinterpretation of environmental monitored data has been applying the multiple variable analyses methods for variables classification and modeling the environmental data [25]. The multivariate statistical techniques are also the appropriate tool for a meaningful data reduction and interpretation of multi-constituent chemical and physical measurements [17]. The multiple variable analyses have been widely used as unbiased methods in analysis of water quality data for drawing the

However, in this study, the raw data sets that obtained from monitoring process have used in the statistical models without any preprocess steps because importance in testing the model performances to forecast the upper and lower limits of wastewater parameters. The performance of selected statistical models was evaluated and discussed according to the root mean square error (RMSE). The statistical significant terms in forecasting the models along with the results of tests on error residuals were run to determine whether each model was adequate for this data.

This process was used for finding the correlation coefficients between COD and EC of the exceeding wastewater, and other loaded factors. The curve fitting approach was also utilized to consider the several linear and nonlinear models for simulating their correlations. Time series analyses were applied, due to the non-significant correlation between these variables.

The statistical techniques for analyzing the time-series data have been included the range 
126 from simple to very complex. However, the first step in such analyses is always to identify the 127 characteristics of data, thus the multiple range tests are performed by using the correlation 128 analyses to test all the pairwise comparisons among daily series means of each monitored 129 parameter. Time series analysis was applied to establish the general trend of each effluent 130 parameter. In the time series analysis, it is assumed that the data consists of a systematic pattern 131 (identifiable component) and random noise (error), which makes the pattern difficult to assess. 132 The most of time series analyses techniques involve some form of filtering out noise in order to 133 make the pattern more salient [9]. The models of time series data have many forms and 134 represented different in the modeling processes. During modeling variations in the level of a 135 process, three broad classes of practical importance are the autoregressive (AR) models, the 136 integrated (I) models, and the moving average (MA) models. This one class depends linearly on 137 previous data points. Combinations of these ideas produce autoregressive moving average 138 (ARMA) and autoregressive integrated moving average (ARIMA) models. Special attention has 139 accorded to ARIMA model, which estimates and forecasts using the methods prescribed by [4, 140 5].

This study thus designed that the exceeded variables of COD or EC were the output of 142 models and other loaded factors were the inputs parameters. Since, data set of the inputs and 143 outputs factors had not the significant correlation with together, here was assumed that having 144 the significant correlation at log-time, i.e., one to three days. This idea was generated due to the 145 retention time of wastewater on zeolite channel is the key index to be an effect on the exceeded 146 water quality. Hence, the models of time series analysis, i.e., ARIMA were used, then the curve 147 fitting approach were utilized to achieve the simulation model based on the relationship between 148 the normalized data of exceeded daily COD and loaded TDS on previous day. In such process 
needs to normalize data as following:

$$
\left(\mathrm{X}_{\max }-\mathrm{X}_{\mathrm{i}}\right) /\left(\mathrm{X}_{\max }-\mathrm{X}_{\min }\right)
$$

Where $\mathrm{X}_{\max }$ and $\mathrm{X}_{\min }$ are the maximum and minimum values of input or output variables.

The several linear and nonlinear models based on the curve fitting approach were used to find a simulation model based on defining the relationship between the normalized data of the daily exceeded of COD, and the loaded of TDS at previous day, resulting the achieved regression coefficient was less than 0.5. To improve the results of simulation process applied these relationships clustering analysis (CA) in line with the fuzzy inference system (FIS). The cluster analysis was also utilized to develop the meaningful aggregations of groups of entities based on a large number of interdependent variables. The purpose was specifically classified for sample of entities into smaller number of the mutually exclusive groups based on the multivariate similarities among entities [18]. The CA was divided a large number of objects into the smaller number of homogeneous groups under the basis of their correlation structure.

A fuzzy inference system (FIS) included a fuzzy rule-based system is a nonlinear mapping of a given input vector to a scalar output vector by using fuzzy logic. Fuzzy rules have proven to be effective for specifying how a given system should operate. Inference, "then" was defined as a procedure for deducing new facts out of existing ones in the basis of formal deduction rules. Classical mathematical tools (e.g., two-valued predicate logic, differential equations) are not well suited for dealing with ill-defined and uncertain systems. By contrast, a fuzzy inference system employing fuzzy IF-THEN rules allows for a higher degree of flexibility and expressivity to cope with problems that are too complex for exact solution but do not require a high degree of precision $[39,13]$. FISs have been successfully applied in many fields, such as 
171 control systems [7, 22], time series forecasting [20], intelligent robots [37], decision analysis [6], 172 expert systems, and computer vision.

An FIS is based on fuzzy set theory, fuzzy IF-THEN rules and fuzzy inference theory,

174 the architecture of which includes five major components: fuzzifier, rules, membership functions

175 (MFs), inference engine and defuzzifier (as shown in Figure 2). Rules are the core of an FIS and

176 can be extracted from historical data or generated from human knowledge. To extract rules from

177 the numerical training data through learning or clustering algorithms is commonly to be using for

178 industrial applications and academic researches. In this study, the rules expressed as a collection

179 of fuzzy IF-THEN rules and extracted from the cluster analysis.

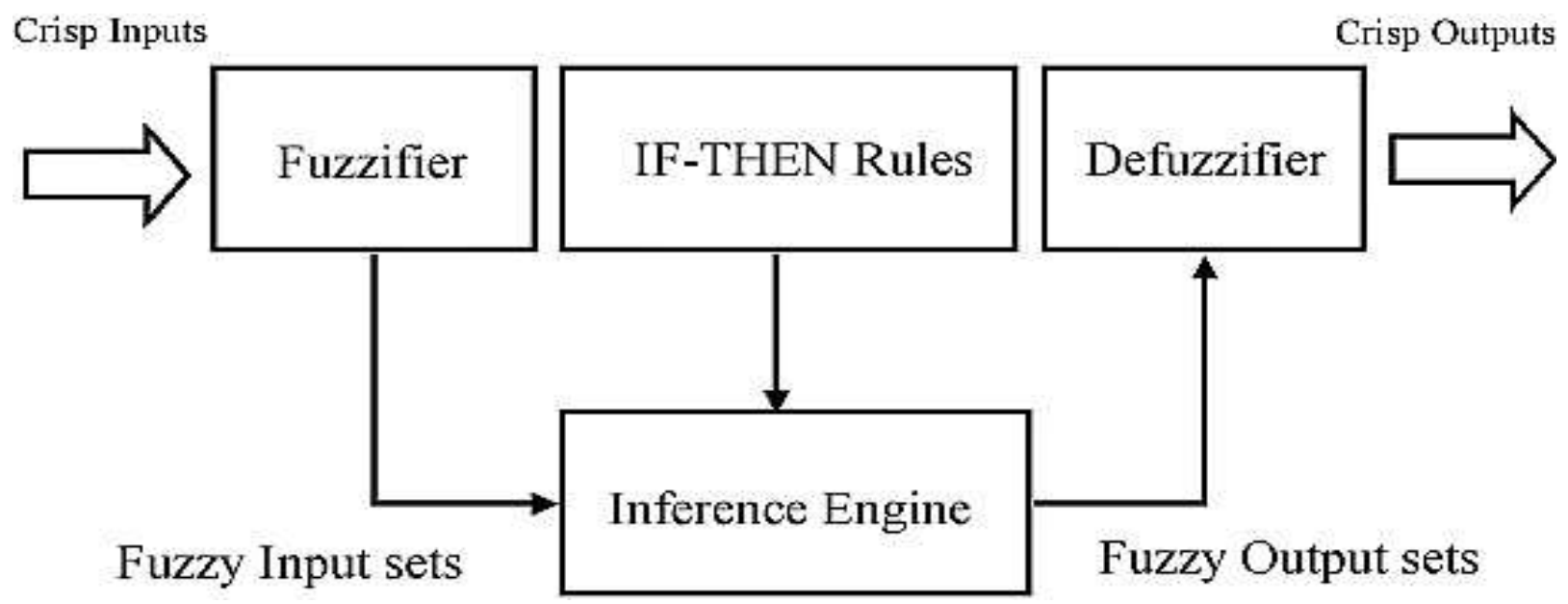

182 Figure 2. Architecture of fuzzy inference system.

In the basis of a set of fuzzy IF-THEN rules, the inference engine maps fuzzy input sets

184 into fuzzy output sets through the fuzzy operations, such as T-norm and T-conorm. There only 185 focus on algebraic product, one kind of T-norm operations, for fuzzy intersection. The T-norm 186 operators can be thought of as the extension for fuzzy AND operations and have many kinds of 
187 operations, e.g., algebraic product, logical product and bounded product [32]. Membership

188 functions used in the terms appear in the antecedents and consequents of fuzzy IF-THEN rules.

189 The common shapes of membership functions are triangular, trapezoidal, piecewise linear,

190 Gaussian and bell-shaped functions. Owing to the statements of IF-THEN rules, the fuzzifier

191 maps a crisp input set into a fuzzy input set that a crisp variable is characterized by an

192 appropriate membership function.

The final component, the defuzzifier, converts a fuzzy output of inference engine to a 194 crisp output. Through the aforementioned procedure, FIS formulates the mapping from an input 195 vector into a scalar output, whose relationship can be expressed as $y=f(x)$. The two most 196 common FISs are Mamdani [16] and Takagi-Sugeno-Kang (TSK) [29, 30]. They both have the

197 same antecedent structures, but have the different consequent structures. The consequent parts of 198 Mamdani's fuzzy rules are fuzzy sets, while those of TSK's fuzzy rules are functions defined by 199 below equation [20]: 203 as the consequent part. 
The popular statistical analysis has usually used to study the statistical characteristic of 208 data on the wastewater variables included central tendency, variability, and shape. There have 209 the standardized skewness and standardized kurtosis that to be applied to determine whether the 210 sample having the normal distribution, the statistics outside of the range of -2 to +2 indicates 211 significant departures from normality and would tend to invalidate many of the statistical 212 procedures that normally applied on the data. The standardized skewness values outside expected 213 range for the followed variables were shown In Table 2. The Multiple-Variable Analysis was 214 applied to build models for predicting the exceeded values of EC and COD from other loaded 215 factors. The days of 100 monitoring data from wastewater treatment station were applied to 216 analyze multi-variable correlation, correlation coefficient, and P-values at over 95\%, and the 217 results showed in Table3.

220 Table 2

221 Summary statistics for each of the wastewater data variables

\begin{tabular}{ccccccccc}
\hline & TSS(ppm) & TEM & TDS(ppm) & PH & EC(mgl) & COD(ppm) & EC & COD \\
Item & Input & Input & Input & Input & Input & Input & Output & Output \\
\hline Count & 100 & 100 & 100 & 100 & 100 & 100 & 100 & 100 \\
Average & 51.26 & 19.11 & 1566 & 8.60 & 2368 & 98.21 & 1507 & 62.57 \\
St. deviation & 6.37 & 0.53 & 590 & 0.27 & 569 & 19.59 & 152 & 13.80 \\
Variation Coefficient & $12.44 \%$ & $2.80 \%$ & $37.68 \%$ & $3.14 \%$ & $24.05 \%$ & $19.95 \%$ & $10.11 \%$ & $22.07 \%$ \\
Minimum & 40 & 18 & 850 & 8 & 1690 & 80 & 1200 & 34 \\
Maximum & 72 & 21 & 3300 & 9 & 4000 & 180 & 1750 & 83 \\
Range & 32 & 3 & 2450 & 1 & 2310 & 100 & 550 & 49
\end{tabular}




\begin{tabular}{ccccccccc} 
St. skewness & 3.46 & 2.46 & 4.86 & -1.37 & 4.00 & 8.72 & -1.48 & -2.97 \\
St. kurtosis & 1.95 & 1.99 & 1.93 & -0.99 & 0.83 & 10.97 & -1.45 & -1.11 \\
\hline
\end{tabular}

225 water quality, the relationship between loaded and excess variables was considered. The best 226 correlation coefficient associated with the acceptable p-vale was obtained from the exceeded

227 values of EC and the loaded values of TSS for each day (Fig 3), besides the exceeded values of 228 COD had the most level of regression by the loaded values of TDS. As a result, the equations 229 form of the exceeded values of COD and EC along with the loaded values of TDS and TSS at the 230 same time can be shown as following:

$231 \quad \operatorname{COD}_{\mathrm{E}}(\mathrm{t})=\mathrm{F}\left(\mathrm{TDS}_{\mathrm{L}}(\mathrm{t})\right)$

$232 \quad \mathrm{EC}_{\mathrm{E}}(\mathrm{t})=\mathrm{F}\left(\mathrm{TSS}_{\mathrm{L}}(\mathrm{t})\right)$

233 Since the electrical current conduction has been directly related to the concentration of 234 dissolved salts in water and thus to total dissolved solids (TDS), the electrical conductivity 235 method has been using as a measurement approach of capacity solved salts into water. Dissolved 236 salts into the positively charged ions and the negatively charged ions, which has made the 237 electricity circuit. Hence, the observed relationship between the exceeded of EC and the loaded 238 of TSS was demonstrated that the concentration of Zeolite had not the effect significant on 239 wastewater treatment process under the salt pollution. The reason of such results was that the 240 some factories, the wastewater has been released into collection network, which their extra salt 241 were more than the beyond Zeolite filtration capacity. 

respectively (Table 3). Although, the relationship between COD and TDS is not the significant 244 difference with the relationship between COD and TSS, measuring the TDS is easier than the 245 TSS, thus to estimate the COD, Eq. (2) was selected. The filtration capacity reduces because 246 decreases the Zeolite ion exchanges that is its most important characteristic, resulting the extra 247 loaded of suspended and dissolved solid from the small factories into collection network could 248 be the basic challenge to increase the exceeded values of EC and COD.

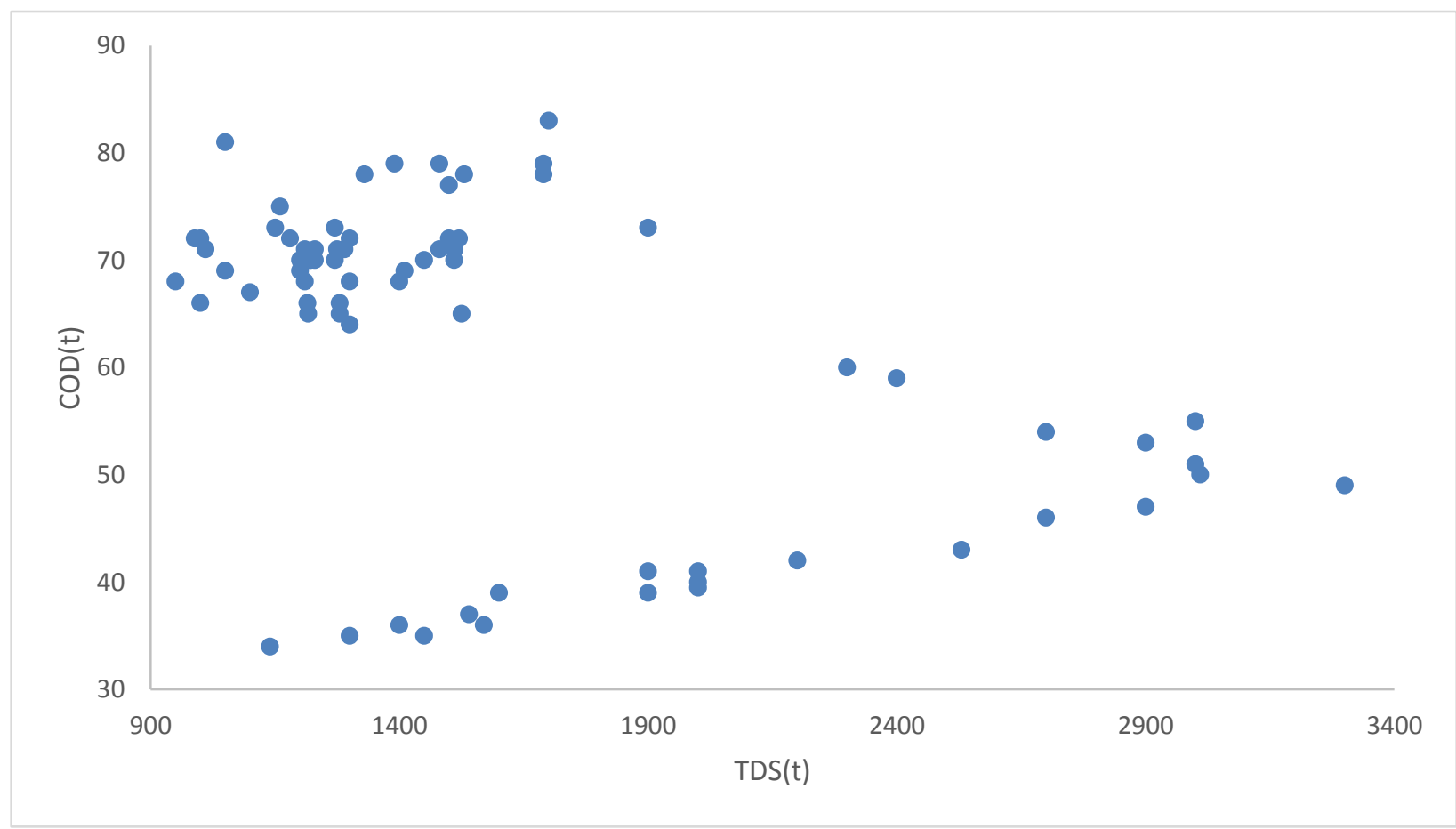

250 Figure 3. The exceeded values of Chemical Oxygen Demand (ppm) and the loaded values of 251 Total Dissolved Solid (ppm) on $\mathrm{t}^{\text {th }}$ day. 
260 Table 3

261 The Pearson product moment correlations between each pair of wastewater data variables; the 262 indexes of "E" and "L" define as the exceeded values and the loaded values, respectively.

\begin{tabular}{ccccccccc}
\hline Variable & $\mathrm{COD}_{\mathrm{E}}$ & $\mathrm{EC}_{\mathrm{E}}$ & $\mathrm{COD}_{\mathrm{L}}$ & $\mathrm{EC}_{\mathrm{L}}$ & $\mathrm{PH}_{\mathrm{L}}$ & $\mathrm{TDS}_{\mathrm{L}}$ & $\mathrm{TEM}_{\mathrm{L}}$ & $\mathrm{TSS}_{\mathrm{L}}$ \\
\hline $\mathrm{COD}_{\mathrm{E}}$ & & 0.816 & 0.467 & -0.415 & -0.159 & -0.472 & -0.165 & 0.395 \\
& & 0 & 0 & 0.0002 & 0.170 & 0 & 0.155 & 0.0004 \\
$\mathrm{EC}$ & & & & & & & & \\
$\mathrm{E}$ & 0.816 & & 0.197 & -0.348 & -0.210 & -0.463 & -0.357 & 0.535 \\
& 0 & & 0.087 & 0.002 & 0.068 & 0 & 0.002 & 0 \\
$\mathrm{COD}_{\mathrm{L}}$ & 0.467 & 0.197 & & -0.357 & -0.089 & -0.094 & 0.214 & -0.055 \\
& 0 & 0.087 & & 0.001 & 0.443 & 0.418 & 0.063 & 0.636 \\
$\mathrm{EC}_{\mathrm{L}}$ & -0.415 & -0.348 & -0.357 & & 0.189 & 0.843 & 0.113 & -0.099 \\
& 0.0002 & 0.002 & 0.001 & & 0.100 & 0 & 0.329 & 0.394 \\
$\mathrm{PH}_{\mathrm{L}}$ & -0.159 & -0.210 & -0.089 & 0.189 & & 0.278 & 0.001 & 0.023 \\
& 0.170 & 0.068 & 0.443 & 0.100 & & 0.015 & 0.990 & 0.844 \\
$\mathrm{TDS}_{\mathrm{L}}$ & -0.472 & -0.463 & -0.094 & 0.843 & 0.278 & & 0.234 & -0.210 \\
& 0 & 0 & 0.4182 & 0 & 0.015 & & 0.0416 & 0.0675 \\
$\mathrm{TEM}_{\mathrm{L}}$ & -0.165 & -0.357 & 0.214 & 0.113 & 0.001 & 0.234 & & -0.284
\end{tabular}




\begin{tabular}{ccccccccc} 
& 0.155 & 0.001 & 0.063 & 0.329 & 0.990 & 0.041 & & 0.013 \\
$\mathrm{TSS}_{\mathrm{L}}$ & 0.395 & 0.535 & -0.055 & -0.099 & 0.023 & -0.210 & -0.284 \\
& 0.0004 & 0 & 0.636 & 0.394 & 0.844 & 0.067 & 0.013 \\
\hline
\end{tabular}

The variations of exceeded values of COD with the loaded values of TDS presented in Fig.

2653 has been compatible with their lack correlation coefficient, thus the highest regression

266 coefficient of linear and non-linear models tested to simulate their changes were 0.5. As a

267 sequence of attempt to test through the time-series analyses such as ARIMA has assumed the

268 existed log-time from one to three days between the loaded variables, i.e., TSS and TDS. The

269 retention time of wastewater in Zeolite channel is generally a key index for effecting on the

270 exceeded water quality, thus these analyses and models were necessary.

271 The five models of ARIMA compared for selecting the best time-series (Table 4),

272 resulting the one day log has been better matching on other models, so that predicted daily

273 changes of TSS and TDS by their value of one day before. This model has predicted the

274 exceeded values of EC and COD at the time of through the loaded values of TSS and TDS at

275 the time of $\mathrm{t}-1$. As a result, the decision maker could have the optimization analysis by the means

276 of practical strategies to change the collection network or the capacity of Zeolite filtration.

277 Therefore, Eq. 2 and 3 have adjusted to detect the correlation above variables at different time.

$278 \operatorname{COD}_{\mathrm{E}}(\mathrm{t})=\mathrm{F}\left(\mathrm{TDS}_{\mathrm{L}}(\mathrm{t}-1)\right)$

$279 \quad \mathrm{EC}_{\mathrm{E}}(\mathrm{t})=\mathrm{F}\left(\mathrm{TSS}_{\mathrm{L}}(\mathrm{t}-1)\right)$

282 The results of time-series analysis for the loaded values of TDS.

\begin{tabular}{ccccccc}
\hline Model & RMSE $^{*}$ & MAE & MAPE & ME & MPE & AIC \\
\hline ARIMA(1,0,0) & 3.76 & 2.91 & 5.66 & 0.007 & -0.493 & 2.698 \\
\hline
\end{tabular}




\begin{tabular}{lllllll}
\hline ARIMA(2,0,0) & 3.78 & 2.87 & 5.57 & 0.012 & -0.478 & 2.729 \\
ARIMA(1,0,1) & 3.78 & 2.88 & 5.59 & 0.010 & -0.482 & 2.730 \\
ARIMA(1,0,2) & 3.75 & 2.79 & 5.43 & 0.054 & -0.377 & 2.734 \\
ARIMA(0,1,0) & 3.95 & 2.96 & 5.75 & -0.083 & -0.465 & 2.747 \\
\hline
\end{tabular}

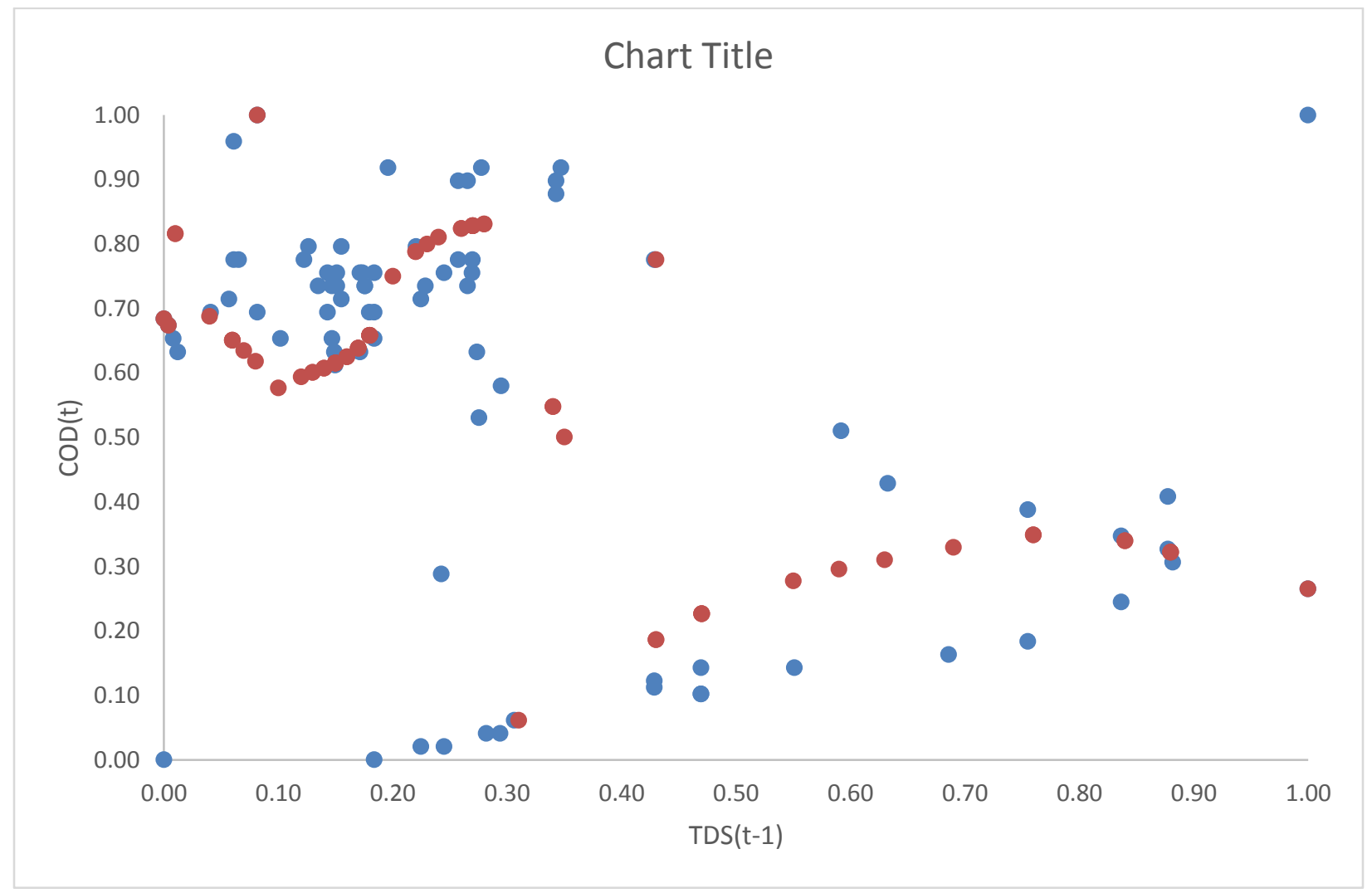

*RMSE, the root mean squared error, MAE, the mean absolute error, MAPE, the mean absolute percentage error, $\mathrm{ME}$, the mean error, MPE, the mean percentage error.

Using the curve fitting approach with and without the normalized data to achieve any function of the $\mathrm{COD}_{\mathrm{E}}(\mathrm{t})$ based on the $\operatorname{TDS}_{\mathrm{L}}(\mathrm{t}-1)$ and $\mathrm{ECE}(\mathrm{t})$ with $\mathrm{TSS}_{\mathrm{L}}(\mathrm{t}-1)$ has not improved the regression coefficient for linear and nonlinear functions. The weak relationships between $\mathrm{COD}_{\mathrm{E}}(\mathrm{t})$ and $\operatorname{TDS}_{\mathrm{L}}(\mathrm{t}-1)$ has explained how the data distribution shown in the Fig. 4. The classification analysis of data distribution based on the data normalized average K-means has used in this study (Table 5). 
293 Figure 4. The exceeded values of chemical oxygen demand (COD) in the day of $t$, and the loaded 294 values of total dissolved solid (TDS) in the day of $\mathrm{t}-1$. The triangular points demonstrated the 295 estimated values of COD in the day of $\mathrm{t}$ by the TDS in the day of $\mathrm{t}-1$, and the circular points 296 demonstrated the results of Mamdini’s fuzzy inference system model.

297 Table 5

298 The results of clustering analysis for the loaded values of TDS and TSS in the day of $\mathrm{t}-1$, and the 299 exceeded values of COD and EC in the day of $t$.

\begin{tabular}{ccc}
\hline Cluster & COD & TDS \\
\hline $\mathbf{1}$ & 0.856 & 0.297 \\
$\mathbf{2}$ & 0.331 & 0.775 \\
$\mathbf{3}$ & 0.075 & 0.362 \\
$\mathbf{4}$ & 0.749 & 0.166 \\
$\mathbf{5}$ & 0.643 & 0.123 \\
& TSS & $\mathbf{E C}$ \\
$\mathbf{1}$ & 0.645 & 0.833 \\
$\mathbf{2}$ & 0.296 & 0.658 \\
$\mathbf{3}$ & 0.254 & 0.270 \\
\hline
\end{tabular}
until the TDS has in moderate or high class, resulting it assumed that this trend has the fuzzy 304 behavior, and the fuzzy inference systems (FIS) can be appropriated to simulate this distribution. 305 Therefore, in the first, the membership functions of input e.g., $\mathrm{TDS}_{\mathrm{t}-1}$, and output e.g., $\mathrm{COD}_{\mathrm{t}}$ 
variables in Mamdini's approach was defined based on the average of each class. In this way, the

307 five classes e.g. very low, low, normal, high and very high have described for both variables,

308 such that the functions as "very very low" and "very very high" used to define the extreme states

309 as 0 and / or 1, respectively; each input and output variables includes the seven bell membership

310 functions (Fig. 5). The Mamdani's modeling process is generally to be needed a supervisor that

311 known as the trend training. In this study, the major classes of data distribution had supervisor

312 role, and based on their relationships, the seven fuzzy rules were defined such that the Fuzzy

313 function results of the variables of input e.g., $\operatorname{TDS}_{\mathrm{t}-1}$ and output $\mathrm{COD}_{\mathrm{t}}$ can be established as

314 follows:

315

316

317

318
Rules no. 1: If $\mathrm{TDS}_{\mathrm{t}-1}$ is very very low then $\mathrm{COD}_{\mathrm{t}}$ is very very high.

Rules no. 2: If $\mathrm{TDS}_{\mathrm{t}-1}$ is very low then $\mathrm{COD}_{\mathrm{t}}$ is normal.

Rules no. 3: If $\operatorname{TDS}_{\mathrm{t}-1}$ is low then $\mathrm{COD}_{\mathrm{t}}$ is high.

Rules no. 4: If $\mathrm{TDS}_{\mathrm{t}-1}$ is normal then $\mathrm{COD}_{\mathrm{t}}$ is very high.

Rules no. 5: If $\mathrm{TDS}_{\mathrm{t}-1}$ is high then $\mathrm{COD}_{\mathrm{t}}$ is very high.

Rules no. 6: If $\mathrm{TDS}_{\mathrm{t}-1}$ is very high then $\mathrm{COD}_{\mathrm{t}}$ is low.

Rules no. 7: If $\operatorname{TDS}_{\mathrm{t}-1}$ is very very high then $\operatorname{COD}_{\mathrm{t}}$ is very very low.

In the next step, an artificial test dataset of $\mathrm{TDS}_{\mathrm{t}-1}$ from 0 to 1 created and used in above FIS model in order to the demonstration of the features of simulation model (Fig. 5); after that calculated the values of $\mathrm{COD}_{\mathrm{t}}$ which obtained according to measurment of the TDS (t-1) by using this model resulting they has shown in Fig. 4. 

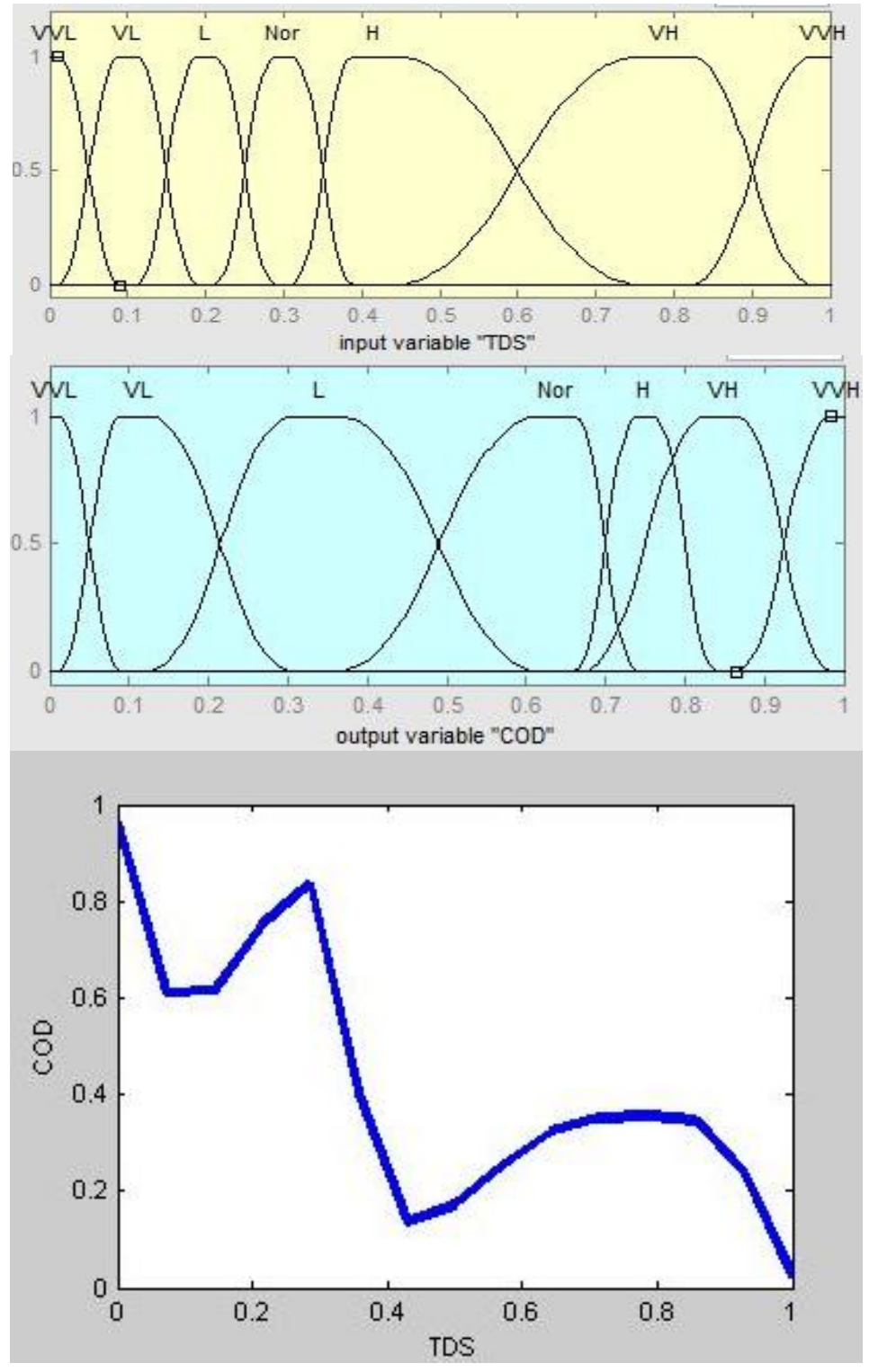

Figure 5. The output's membership functions of the exceeded values of COD in the day of t, and

331 the input's membership functions of the loaded values of TDS in the day of t-1 in line with the 332 results of Mamdini’s fuzzy inference system.

The results of validation process of FIS model presented in Fig. 5, has obtained by 
336 simulation model had been good corresponding (e.g. R2 $=0.764$ ) with the distribution of 337 measured and observed data of COD (t) while was compared by the line of $1: 1$. Here is 338 concluded that the assumption of Fuzzy behavior could be used to explain the trend distribution 339 of $\mathrm{TDS}_{\mathrm{t}-1}$ and $\mathrm{COD}_{\mathrm{t}}$.

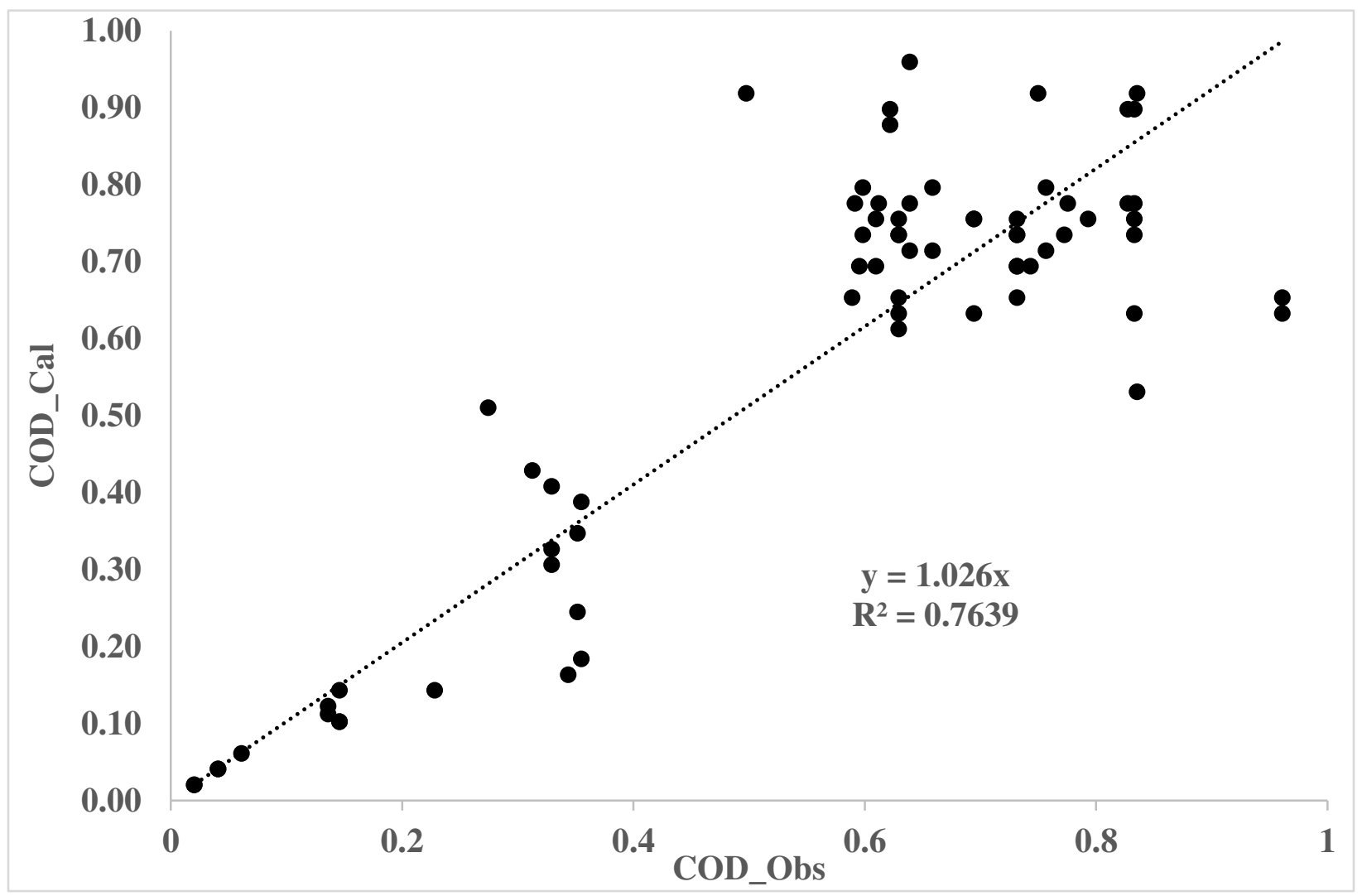

Figure 6. The results of comparing the amounts of estimated and observed of exceeded COD. conversely, if the $\mathrm{TDS}_{\mathrm{L}}$ was "high" then the $\mathrm{COD}_{\mathrm{E}}$ was "low", so that there had closed to the 345 standard level. This result indicated the capacity of Zeolite filtering could be affected by other 
346 factors. The input of "Low" for TDS observed when the rainfall had occurred, thus TDS of the 347 entered wastewater content was affected by runoff, such that the values of $\operatorname{TDS}_{\mathrm{L}}$ had decreased 348 due to the volume of wastewater increased during this condition. In this condition, the loaded 349 wastewater was more than the daily filtering capacity of Zeolite channel. Although the value of 350 TDS was low, the volume of wastewater entering into the treatment plant had high then Zeolite 351 channel so that here could not be appropriately operated its ion exchange capacity. Its filtration 352 operation had better, when the few wastewater along with the more value of TDS entered to the 353 Zeolite channel. Finally, this result can be achieved to manage, that the loaded amount of 354 wastewater treatment pollutants and the mass-transfer of wastewater in line with Zeolite channel 355 should be controlled together.

357 the variations of $\mathrm{EC}_{\mathrm{E}}$ with of $\mathrm{TTS}_{\mathrm{L}}$ were less than 0.5 , and after that used the curve fitting 358 approach with and without normalized data to achieve a function of $\mathrm{EC}_{\mathrm{E}}$ from the day of $\mathrm{t}$ with 359 TSSL from the day of $\mathrm{t}-1$. These approaches couldn't improve the regression coefficient of each 360 linear and nonlinear function too $[34,12]$. Based on the results of clustering analysis, the ranges 361 of the $\mathrm{EC}_{\mathrm{E}}$ from the day of $\mathrm{t}$, and $\mathrm{TTS}_{\mathrm{L}}$ from the day of $\mathrm{t}-1$ variables had classified into three 362 major classes. The Mamdani's modeling process was also used to simulate these changes similar 363 there had applied for simulating the relationship between $\operatorname{COD}_{\mathrm{t}}$ with $\operatorname{TDS}_{\mathrm{t}-1}$. The FIS simulation 364 model had not good corresponding with distribution of the measured and observed data of $\mathrm{EC}_{\mathrm{E}}$ 365 from the day of $t$. 


\section{4. Conclusion}

Upgrading the efficiency in wastewater treatment management has the goal of decision

371 maker to model the relationship between input and output variables, due to here needs that these

372 models to evaluate treatment process. Therefore, the purpose of this study has been achieving an 373 appropriate model of the exceeded variables, e.g., COD and EC associated with the loaded

374 variables, e.g., TDS and TSS. The results showed that no significant correlation coefficient were 375 obtained by analyzing approaches such as multivariate, curve fitting with linear and nonlinear 376 models, time series, and clustering with and without normalized data. Hence, the results of

377 variables classification were utilized to define the mean and range of each membership function 378 for the variables of input, i.e., $\operatorname{TDS}_{\mathrm{t}-1}$ and output, i.e., $\mathrm{COD}_{\mathrm{t}}$.

The Fuzzy rules could been described the data distributions of input and output variables, 380 wherein other deterministic models could not been considering subject matter. The feature of 381 Fuzzy rules in this issue has caused goodness conformity in the estimated and measured values

382 of the exceeded $\mathrm{COD}_{\mathrm{t}}$, i.e., $\mathrm{R}^{2}=0.76$, thus the Fuzzy behavior assumption of data distribution 383 was admitted. The result of simulation model showed that the data distribution function of input 384 variables, $\mathrm{TDS}_{\mathrm{t}-1}$ along with output, $\mathrm{COD}_{\mathrm{t}}$ has formed similar to "S" shape curve, and could been 385 thus used as a reference for the filtration capacity of Zeolite channel.

The certain variations range of TDS have been existing that the filtration by Zeolite could 387 been affected, it is way that beginning of this impact is defined as such critical point, i.e., the 388 threshold amount of TDS. In this point, Zeolite responsibility on the removal COD in wastewater treatment is to be sufficient, for example in this study, TDS threshold was occurred in $1746 \mathrm{ppm}$ 
390 in line with COD was 52 ppm (Fig. 5). Although the others of research have been trying to 391 improve treatment efficiency from the direct determination of Zeolite quantity, the obtained 392 results of our study indicated that the fixed value of soluble solids concentration into mass393 transfer of wastewater entering on treatment plant in the Zeolite filtration effectiveness had 394 important role, due to in the view of fact that the filtration capacity was a function of the soluble 395 solids.

397 Availability of data and materials

The datasets used and/or analyzed during the current study are available from the 399 corresponding author on reasonable request.

400

Competing interests

401

The authors declare that they have no competing interests.

$402 \quad$ Funding

403

Author's team has supported all sources of funding for this research.

404 Authors' contributions

405

All authors read and approved the final manuscript.

406

Acknowledgements

407

Not applicable 
410

411

412

413

414

415

416

417

418

419

420

421

422

423

424

425

426

427

428

429

430

431

432

433

434

435

436

437

438

439

440

441

442

443

444

445

446

\section{References}

[1] Al-Shammiri, M. Al-Saffar, A. Bohamad, S., Ahmed, M. (2005). "Waste water quality and reuse in irrigation in Kuwait using microfiltration technology in treatment."J. Desalination, 185, 213-225.

[2] Alvarez-Ayuso, E., Garcia-Sanchez, A., Querol, X. (2003). "Purification of metal electroplating waste waters using zeolites." Water Res, 37(20), 4855-62.

[3] Bixio, D., and Wintgens, T. (2006). "Water Reuse System Management Manual AQUAREC.", Directorate-General for Research, European Commission Brussels, Belgium, AQUAREC - EVK1-CT-2002-00130.

[4] Box, G.E.P.,and Jenkins, G.M. (1976)."Time Series Analysis Forecasting and Control.", Holden-Day, San Francisco, USA.

[5] Box G.E.P., Jenkins G.M., Reinsel, G.C. (1991). "Time Series Analysis, Forecasting and Control.", Prentice Hall, Englewood Cliffs, NJ. USA.

[6] Chaneau, J. L., M. Gunaratne, Altschaeffl, A.G. (1987). "An application of type-2 sets to decision making in engineering, in Analysis of Fuzzy Information.", vol. 2, Artificial Intelligence and Decision Systems, edited by J. Bezdek, CRC Press, Boca Raton, Fla., 145-151.

[7] Chang, L. C., and Chang, F. J. (2001), "Intelligent control for modelling of real-time reservoir operation.", Hydrol. Processes, 15, 1621-1634.

[8] Dobrowolski, J., O’Neill, M., Duriancik, L., Throwe, J. (2008). "Opportunities and Challenges in Agricultural Water Reuse.", Final Report, USDA-CSREES.

[9] Dunea, D., and Iordache, Ş. (2011). "Time series analysis of the heavy metals loaded wastewaters resulted from chromium electroplating process.", Environmental Engineering and Management Journal, 10 (3), 421-434.

[10] Fatta-Kassinos, D., Kalavrouziotis, I.K., Koukoulakis, P.H., Vasquez, M.I. (2011). "The risks associated with wast ewater reuse and xenobiotics in the agroecological environment.", J. Sci Total Environ, 409 (19), 3555-3563.

[11] Hertz, J.A., Krogh, A., Palmer, R.G. (1999)."Introduction to the theory of neural computation.", West view Press: Boulder, CO.

[12] Ibrar I., Altaee, A., Zhou, J. L., Naji, O., Khanafer, D., 2020, Challenges and potentials of forward osmosis process in the treatment of wastewater, Critical Reviews in Environmental Science and Technology, Vol., 50, 13, 2020, Pp. 1339-1383.

[13] Jang, J.-S. R. (1993). "ANFIS: Adaptive-Network-Based Fuzzy Inference System.", IEEE Trans. Syst. Man Cybernetics, 23, 665-685.

[14] Khandaker, S., Toyohara, Y., Saha, G.C., Awual, M.R., Kuba, T., (2020), "Development of synthetic zeolites from bio-slag for cesium adsorption: Kinetic, isotherm and thermodynamic studies”, Journal of Water Process Engineering 33, 101055. 
[15] Liu, B., Khan, A., Kim, K., Kukkar, D., Zhang, M., 2019, The adsorptive removal of lead ions in aquatic media: Performance comparison between advanced functional materials and conventional materials, Critical Reviews in Environmental Science and Technology, https:_/_doi.org/_10.1080 /10643389._2019._1694820.

[16] Mamdani, E. H., and Assilian, S. (1975). "An experiment in linguistic synthesis with a fuzzy logic controller.", Int. J. Man Mach. Stud., 7, 1-13.

[17] Massart, D.L., Vandeginste, B.G.M., Deming, S.N., Michotte, Y., Kaufman, L. (1988). "Chemometrices", A Textbook. Elsevier, Amsterdam.

[18] McGarial, K., Cushman, S., Stafford, S. (2000)."Multivariate statistics for wildlife and ecology research.", Springer, New York.

[19] Meda, A., and Cornel, P. (2010). "Aerated biofilter with seasonally varied operation modesfor the production of irrigation water.", J. Water Sciand Tech, 61 (5), 1173-1181.

[20] Mendel, J. M. (2000), "Uncertainty, fuzzy logic, and signal processing.", Signal Process., 80, 913-933.

[21] Mohan, S., and Gandhimathi, R. (2009). "Removal of heavy metal ions from municipal solid waste leachate using coal fly ash as an adsorbent.", J. Hazard Mater, 169(1-3), 351359.

[22] Pal, K., R. , Mudi, K., Pal, N. R. (2002). "A new scheme for fuzzy rule-based system identification and its application to self-tuning fuzzy controllers.", IEEE Trans. Syst. Man Cybernetics, 32, 470-481.

[23] Pedrero, F., Kalavrouziotis, I., Alarcon, J.J., Koukoulakis, P., and Asano, T. (2010). "Use oftreated municipal wastewater in irrigated agriculture e review of some practicesin Spain and Greece.", J. Agric Water Manage, 97 (9), 1233-1241.

[24] Raghunath, R., Murthy, T.R.S., and Raghavan, B.R. (2002). "The utility of multivariate statistical techniques in hydrogeochemical studies: an example from Karnataka, India."J, Water Res, 36, 2437-2442.

[25] Reisenhofer, E., Adami, G., Favretto, E. (1996)."Heavy metals and nutrients in coastal, surface seawaters (Gulf of Trieste, NorthernAdriatic Sea): an environmental study by factor analysis.", Fresenius J Anal Chem, 354,729-734.

[26] Scott, C.A., Zarazúa, J.A., and Levine, G. (2001). "Urban-wastewater Reuse for Crop Productionin theWater-short Guanajuato River Basin, Mexico.", International Water Management Institute, Colombo, Sri Lanka, Research Report 41.

[27] Simeonov, V., Simeonova, P., Tsitouridou, R. (2004). "Chemometric quality assessment of surface waters two case studies.", J. Chem. and Eng Ecol, 11 (6), 449-469.

[28] Singh, K.P., Malik, A., Mohan, D., Sinha, S. (2004). "Multivariate statistical techniques for the evaluation of spatial and temporal variations in water quality of Gomti River (India) - a case study.", J. Water Res, 38, 3980-3992.

[29] Sugeno, M., and Kang, G. T. (1988). "Structure identification of fuzzy model, Fuzzy Sets Syst.", 28, 15-33.

[30] Takagi, T., and M. Sugeno (1985). "Fuzzy identification of systems and its applications to modeling and control.", IEEE Trans. Syst. Man Cybernetics, 15, 116-132. 
[31] Thomas, W.J, and Crittenden, B.D. (1998). "Adsorption technology and design.", Oxford, Boston, Butterworth-Heinemann.

[32] Tsoukalas, L. H., and R. E. Uhrig (1997). "Fuzzy and Neural Approaches in Engineering.", John Wiley, Hoboken, N. J.

[33] UNESCO-WWAP, (2003). "Water for People Water for Life: The United Nations World Water." , Development Report. , UNESCO and Berghahn Books, New York.

[34] Vo, H.N.P., Ngo, H.H., Guo, W., Chang, S.W., Nguyen, D.D., Chen, Z., Wang, X.C., Chen, R., Zhang, X., 2020, Microalgae for saline wastewater treatment: a critical review, Critical Reviews in Environmental Science and Technology, Vol. 50, 12, 2020, Pp 12241265.

[35] Voncina, D.B., Dobcnik, D., Novic, M., Zupan, J. (2002). "Chemometric characterization of the quality of river water.", Analytica Chimica Acta, 462, 87-100.

[36] Westcot, D.W., and Ayers, R.S. (1985). "Irrigation water quality criteria." , In: Pettygrove, G.S., Asano, T. (Eds.), Irrigation with Reclaimed Municipal Wastewater e a Guidance Manual. Lewis Publishers, Inc., Chelsea, MI.

[37] Wu, K. C. (1996). "Fuzzy interval control of mobile robots.", Comput. Electr. Eng., 22, 211-229.

[38] Yu, H.Q., and Fang, H.P. (2003). "Acidogenesis of gelatin-rich wastewater in an upflow anaerobic reactor: influence of $\mathrm{pH}$ and temperature.", Water research, a journal of the International Water Association (Amsterdam [u.a.] : Elsevier, Pergamon), 37(1), 55-66.

[39] Zadeh, L. A. (1973). "Outline of a new approach to the analysis of complex systems and design processes.", IEEE Trans. Syst. Man Cybernetics, 3, 28-44. 
Figures

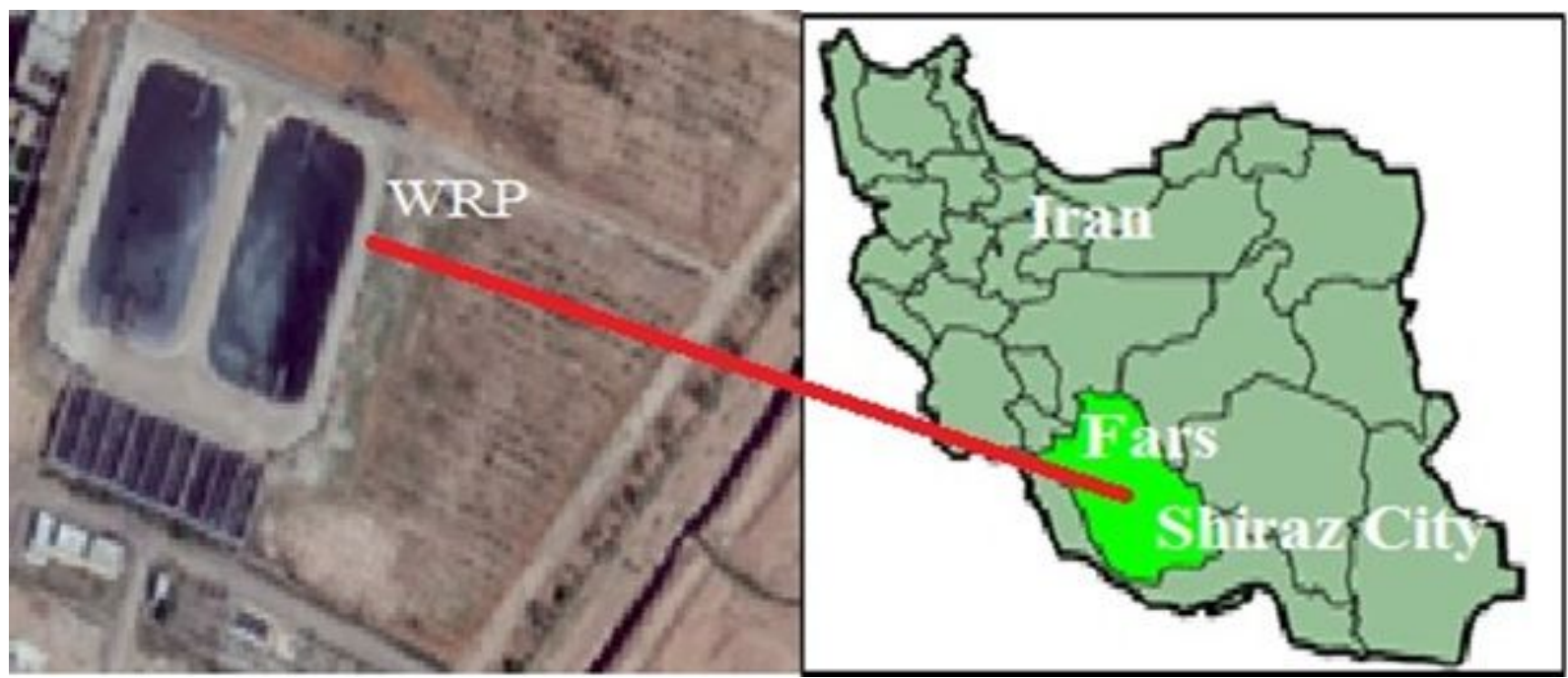

Figure 1

The location map of wastewater station Crisp Inputs
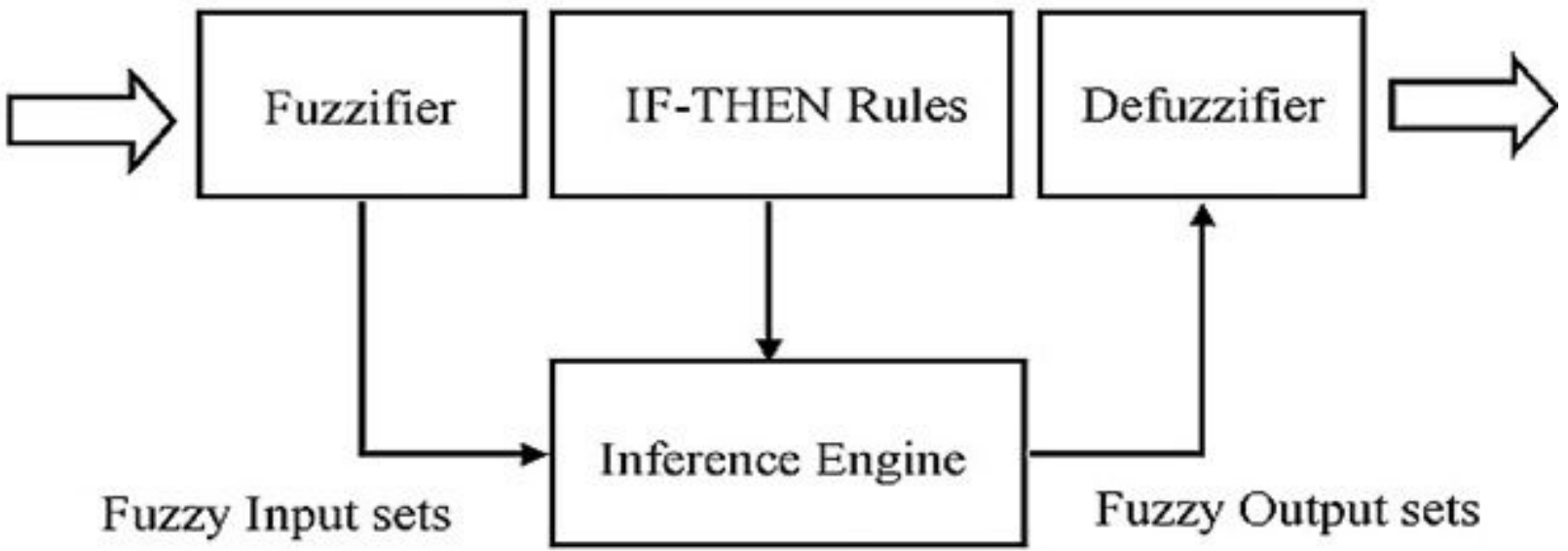

Figure 2

Architecture of fuzzy inference system. 


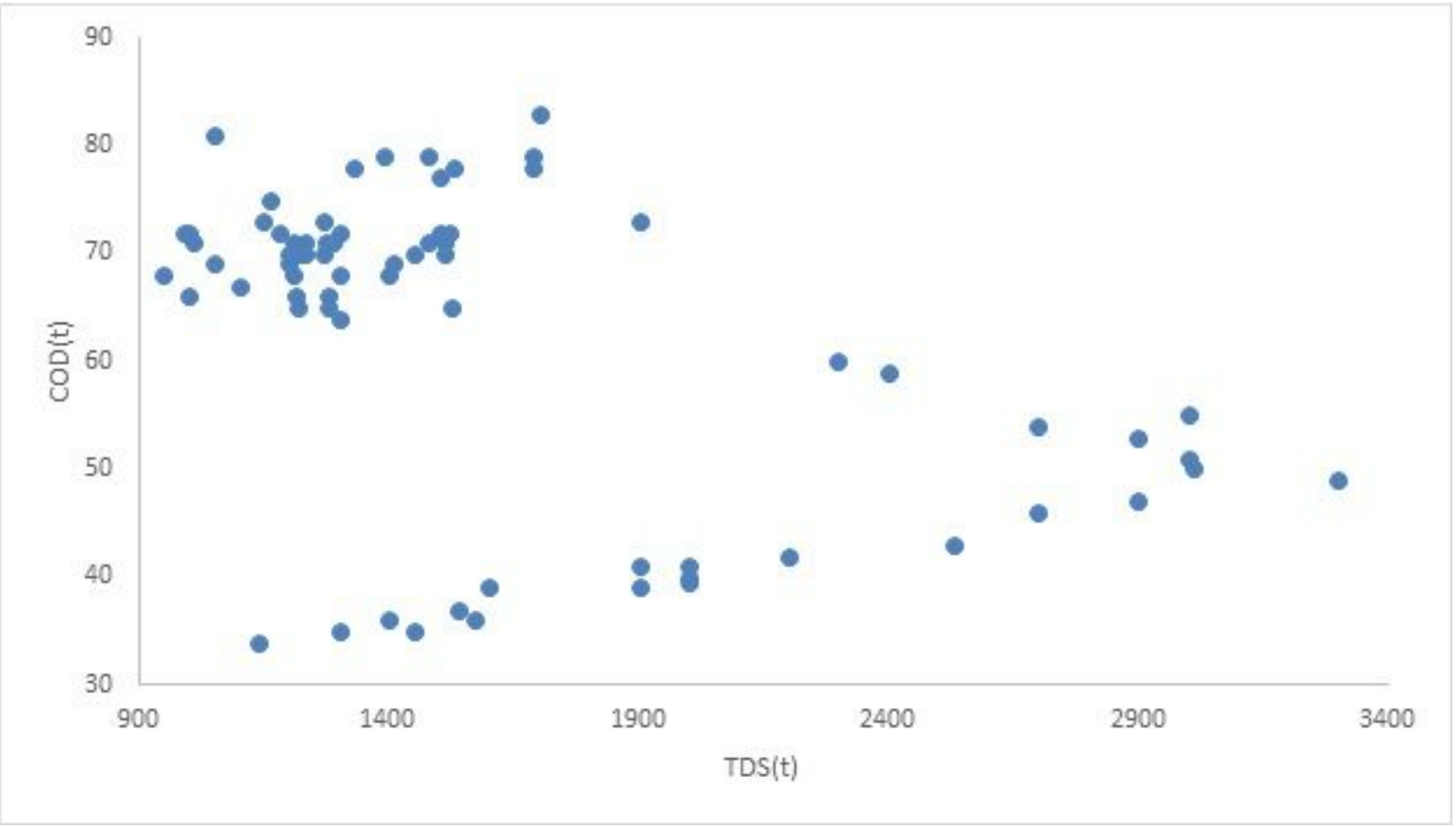

Figure 3

The exceeded values of Chemical Oxygen Demand (ppm) and the loaded values of Total Dissolved Solid (ppm) on tth day.

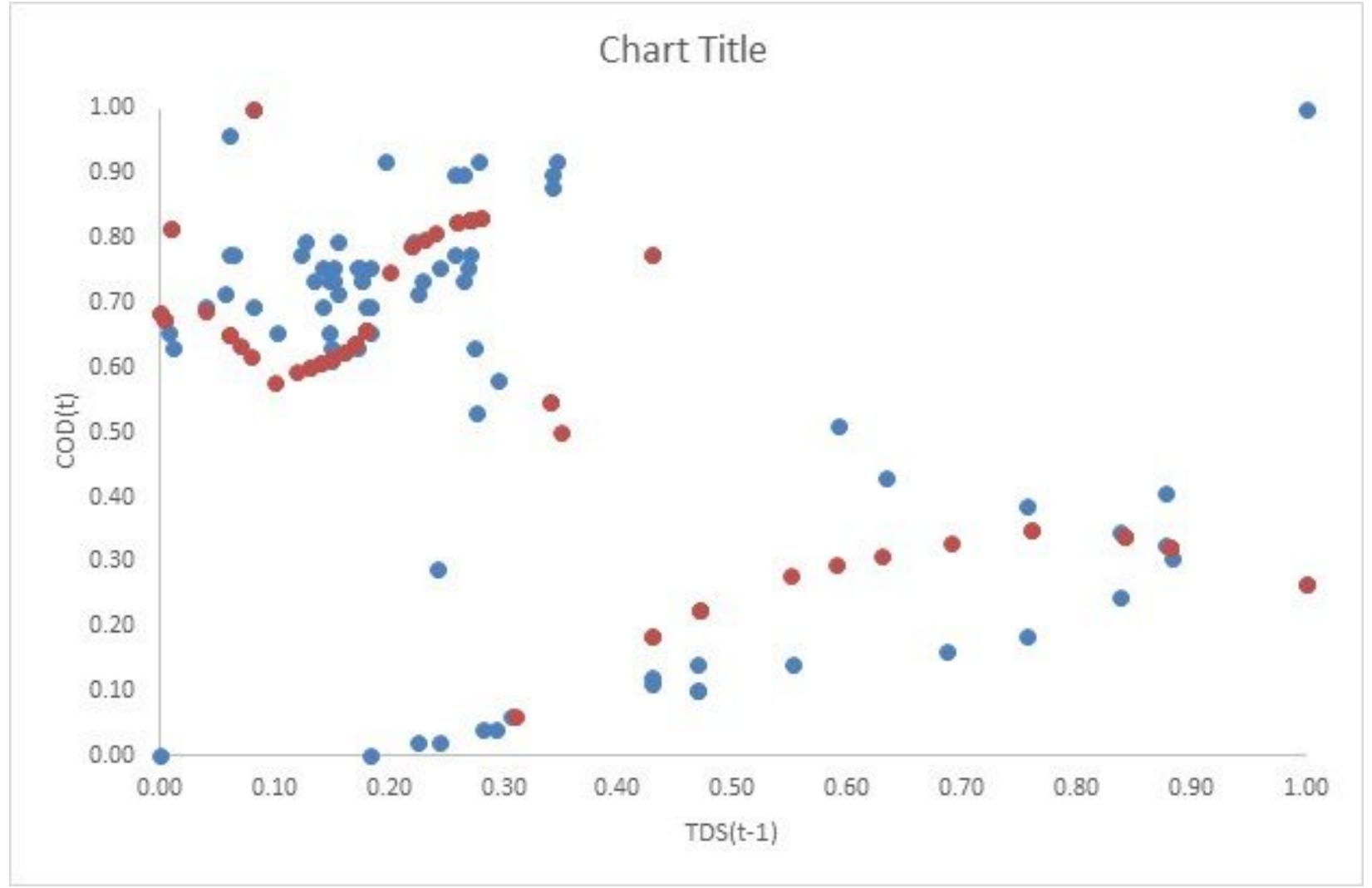

Figure 4 
The exceeded values of chemical oxygen demand (COD) in the day of $t$, and the loaded values of total dissolved solid (TDS) in the day of $t-1$. The triangular points demonstrated the estimated values of COD in the day of $t$ by the TDS in the day of $t-1$, and the circular points demonstrated the results of Mamdini's fuzzy inference system model.
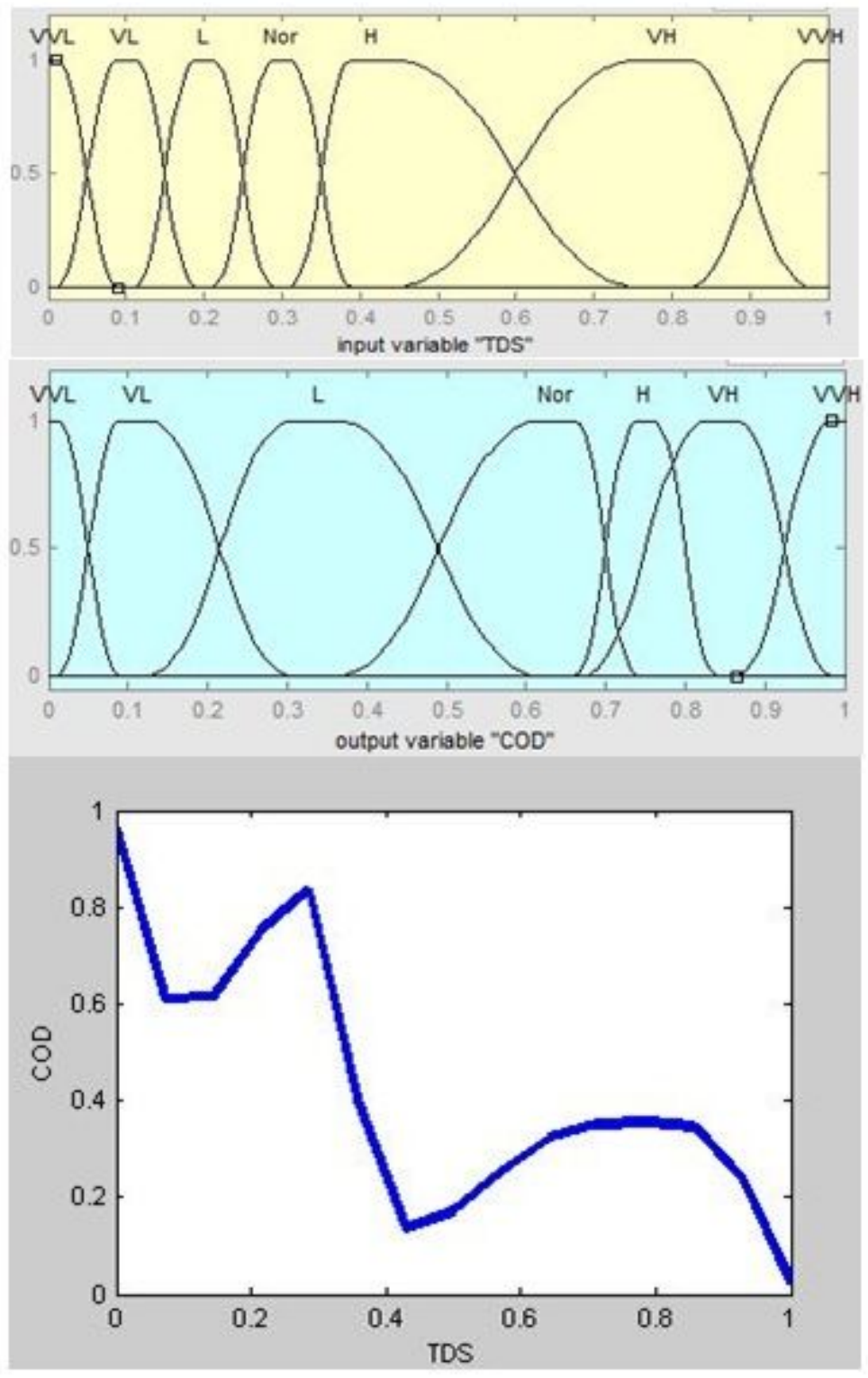

Figure 5

The output's membership functions of the exceeded values of COD in the day of $t$, and the input's membership functions of the loaded values of TDS in the day of $\mathrm{t}-1$ in line with the results of Mamdini's fuzzy inference system. 


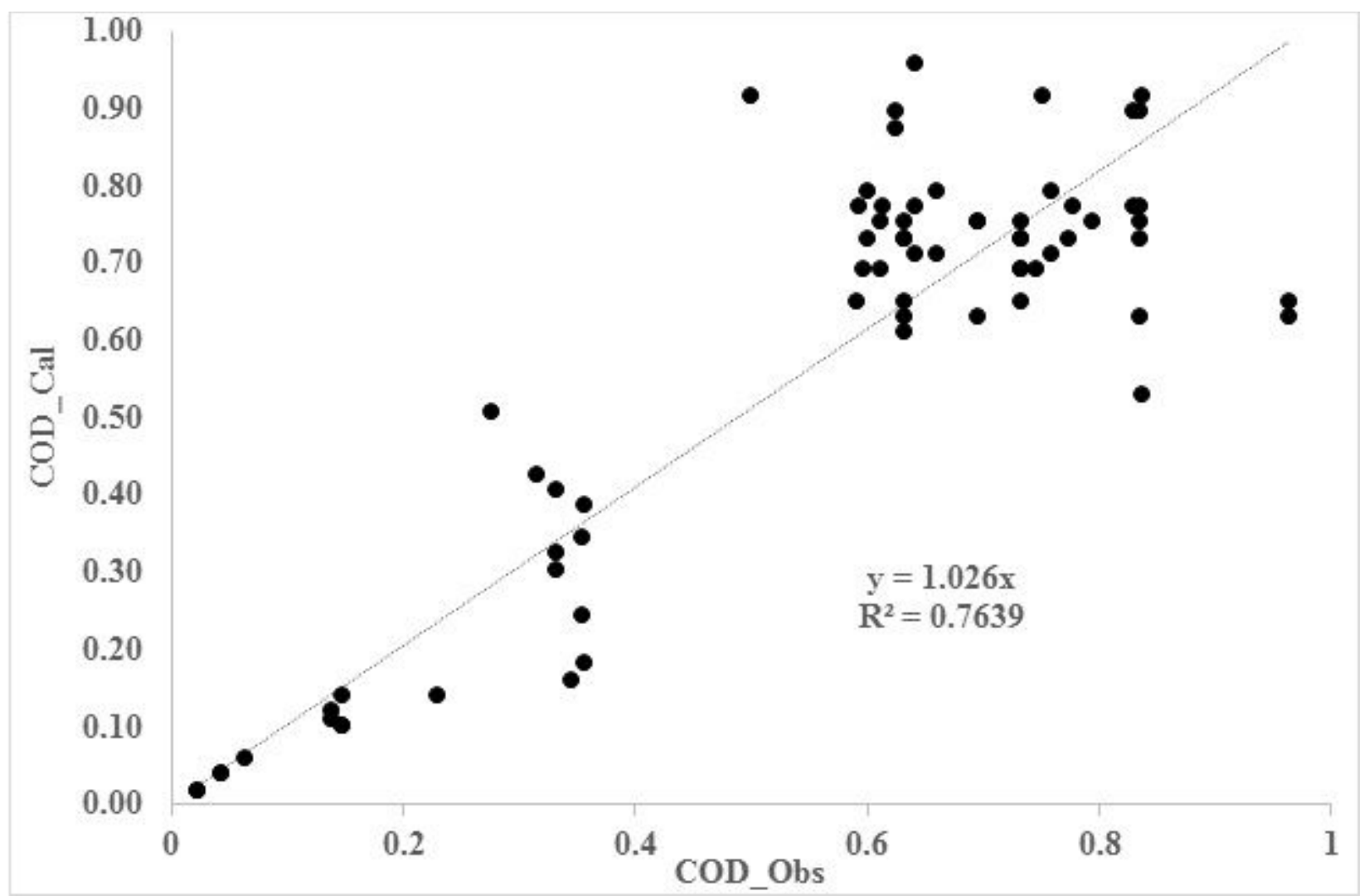

Figure 6

The results of comparing the amounts of estimated and observed of exceeded COD. 